\title{
PELATIHAN LMS WITH EDMODO DALAM PROSES BELAJAR MENGAJAR
}

\author{
${ }^{1}$ Nurkhalik Wahdanial Asbara, ${ }^{2}$ Agunawan, Andi Ircham Hidayat \\ ${ }_{2}^{1}$ STIE Nobel Indonesia Makassar, khalikwahdanial@stienobel-indonesia.ac.id \\ ${ }_{3}^{2}$ STIE Nobel Indonesia Makassar, agunawan@stienobel-indonesia.ac.id \\ ${ }_{3}^{3}$ STIE Nobel Indonesia Makassar, ircham@nobel.ac.id
}

\section{Article history}

Received: 19 Agustus 2021

Revised: 30 September 2021

Accepted: 04 Oktober 2021

\section{Corresponding}

Author:

Nurkhalik Wahdanial

Asbara

STIE Nobel Indonesia

Makassar

Email:

khalikwahdanial@ stienobelindonesia.ac.id

\section{PENDAHULUAN}

Tumbuh kembangnya ilmu pengetahuan dan teknologi informasi, khususnya teknologi informasi komunikasi banyak membawa dampak yang positif bagi berkembangnya dunia informasi dan terlebih khusus lagi pada dunia pendidikan. Pendidikan formal, informal, dan non formal dapat menikmati fasilitas teknologi informasi komunikasi dari yang simpel sampai kepada yang kompleks.

Teknologi informasi yang menggunakan
Tumbuh kembangnya ilmu pengetahuan dan teknologi informasi, khususnya teknologi informasi komunikasi banyak membawa dampak yang positif bagi berkembangnya dunia informasi dan terlebih khusus lagi pada dunia pendidikan. Pendidikan formal, informal, dan non formal dapat menikmati fasilitas teknologi informasi komunikasi dari yang simpel sampai kepada yang kompleks. Format-format pendidikan yang mungkin tersedia di abad ke-21 yaitu Cyber (E-Learning) yang merupakan belajar atau pembelajaran melalui pemanfaatan teknologi informasi komunikasi melalui perangkat komputer dan atau internet, open/distance learning yaitu model pembelajaran jarak jauh, dimana guru dan peserta didik/siswa berada dalam satu tempat yang berbeda tetapi bisa dengan waktu yang sama, serta dengan kemajuan teknolosi saat ini bisa juga dengan bertatap muka melalui kamera tetapi tidak bisa bertatap fisik secara langsung. Tujuan dari penelitian ini adalah guru dan siswa dapat berkomunikasi dengan lancar dalam melakukan proses belajar mengajar .

Kata kunci - Pengetahuan. pembelajaran, edmodo

\section{Abstract}

The growth and development of science and information technology, especially information and communication technology has brought many positive impacts for the development of the world of information and especially in the world of education. Formal, informal, and non-formal education can enjoy information communication technology facilities from the simple to the complex. Educational formats that may be available in the 21 st century are Cyber (E-Learning) which is learning or learning through the use of information and communication technology through computers and or the internet, open/distance learning, which is a distance learning model, where teachers and participants students/students are in a different place but can be at the same time, and with current technological advances it can also be face-toface through the camera but cannot meet physically directly. The purpose of this study is that teachers and students can communicate smoothly in the teaching and learning process using the Edmodo application.

Keyword : Knowledge. learning, edmodo 
keakuratan suatu kabar berita atau informasi, namun juga fasilitas digital dalam multimedia yang dapat membuat belajar lebih menarik melalui visual secara interaktif. Sejalan dengan majunya teknologi internet, banyak kegiatan belajar mengajar yang dapat dilakukan dengan memanfaatkan teknologi komunikasi seperti ini.

Cyber atau electronic learning (ELearning) pada hakekatnya belajar, atau pembelajaran melalui pemanfaatan teknologi komputer atau internet. E-learning adalah salah satu bentuk penggunaan internet yang dapat meningkatkan peran mahasiswa dan peserta didik dalam proses pembelajaran (Saifuddin, 2018). Teknologi belajar secara E-Learning seperti itu bisa juga disebut sebagai belajar atau pembelajaran berbasis Web (web based instruction). Dalam proses belajar mengajar dibutuhkan media yang kreatif dari pengajar agar para siswa/murid dapat lebih cepat untuk memahami dan tertarik dan interaktif dalam proses belajar mengajar (Asbara, 2020). Era informasi dan Era globalisasi adalah merupakan suatu keadaan dimana terjadi proses perubahan antar komunitas, antar budaya, antar negara, antar bangsa, tanpa mengenal batas, ruang dan waktu. Pengaruh perkembangan globalisasi seperti ini semakin terasa, terutama dengan semakin banyaknya saluran informasi komunikasi yang tersedia baik cetak maupun elektronik, serta pesatnya perkembangan dalam bidang teknologi komunikasi dan transportasi.

Penerimaan pengguna teknologi informasi merupakan faktor penting dalam penggunaan dan pemanfaatan sistem informasi yang dikembangkan (Latief \& Nur, 2019).

Format-format pendidikan yang mungkin tersedia di abad ke-21 yaitu Cyber (E-Learning) yang merupakan belajar atau pembelajaran melalui pemanfaatan teknologi informasi komunikasi melalui perangkat komputer dan atau internet, open/distance learning yaitu model pembelajaran jarak jauh, dimana guru dan peserta didik/siswa berada dalam satu tempat yang berbeda tetapi bisa dengan waktu yang sama, serta dengan kemajuan teknolosi saat ini bisa juga dengan bertatap muka melalui kamera tetapi tidak bisa bertatap fisik secara langsung.

Banyak pilihan bagi praktisi pendidikan untuk memanfaatkan TIK dalam proses pembelajarannya, antara lain : Moodle, Prototype, Camtasia, Google Classroom, Schoologi, Edmodo dan masih banyak lagi yang lainya. Dan pada kesempatan ini, penulis hanya membahas
LMS - Edmodo berdasarkan dari pengalaman penulis dalam melakukan kegiatan workshop dan disajikan dalam bentuk tanya-jawab.

Edmodo merupakan platform microblogging pribadi yang dikembangkan untuk guru dan siswa, yaitu dengan mengutamakan privasi siswa guru dan juga siswa dapat berbagi catatan, tautan dan juga dokumen. Di sini guru juga mempunyai kemampuan untuk emngirimkan susuatu dalam rangka waktu yang dapat di lihat publik.

Menurut (Kristiani, 2016), Edmodo merupakan jejaring social untuk pembelajaran Learning Management System (LMS).

Menurut (Agunawan,2020), fungsi dari edmodo adalah mempermudah komunikasi antara murid/mahasiswa dengan guru atau dosen dan sebagai sarana komunikasi belajar. Sebagai tempat untuk ujian dan yang lainya. Dengan semua fitur-fitur yang ada, di dunia maya harus menjadi media yang sempurna untuk meningkatkan kehidupan nyata pendidikan.

\section{METODE PENELITIAN}

Metode yang digunakan dalam melaksanakan kegiatan ini adalah dengan melakukan diskusi dan koordinasi terlebih dahulu kepada peserta yaitu guru dan dosen yang hadir, kemudian dilanjutkan dengan pelatihan pelaksanaan dan sasaran yang ingin dicapai.

Metode yang digunakan dalam kegiatan pengabdian pada Masyarakat ini adalah :

1. Ceramah dan Diskusi

Ceramah dan diskusi dilakukan sebelum kegiatan akan dimulai, sehingga ada koordinasi antara kelompok kerja pengabdian dengan masyarakat (PPM), kemudian kelompok kerja akan melakukan pelatihan berkaitan dengan penggunaan LMS "Edmodo".

\section{Demonstrasi Kegiatan}

Pada kegiatan pelatihan ini kelompok kerja melakukan simulasi menggunakan Aplikasi ELearning "Edmodo" dan berinteraksi dengan siswa.

Adapun langkah-langkah kegiatan dalam pengabdian pada masyarakat ini adalah sebagai berikut :

a. Tahap Persiapan.

- Pra-Survei : Identifikasi permasalahan dalam penggunaan E-Learning dalam dalam masa pandemic

- Pembentukan Kelompok Kerja dalam PKM: Pembentukan Kelompok kerja disesuaikan dengan jenis kepakaran untuk 
menyelesaikan permasalahan yang dihadapi.

- Pembuatan Proposal: Untuk menawarkan solusi permasalahan \& penyediaan dana dalam pelaksanaan pelatihan LMS "Edmodo".

- Persiapan Alat dan Bahan Seminar serta Pelatihan: Pembelian dan Penyewaan alat serta Pembuatan materi kegiatan

b. Tahap Pelaksanaan (Kegiatan dilaksanakan Secara Online Melalui Aplikasi Zoom)

- Workshop Edmodo : menyampaikan tentang E-Learning Edmodo dan penggunaannya

- Simulasi Aplikasi E-Learning "Edmodo"

- Pendampingan Melalui Aplikasi Whatsapp

c. Evaluasi Program

Dilakukan dengan membandingkan kondisi beberapa guru sebelum dan sesudah pelaksanaan program. Indikator keberhasilan program dengan adanya perubahan positif dari guru setelah pelaksaan program.

Kegiatan Pengabdian Kepada Masyarakat dengan tema Pelatihan LMS With Edmodo Dalam Proses Belajar Mengajar dilaksanakan pada tanggal 20-23 Juni 2020 Melalui Aplikasi Zoom. Setelah pelatihan dilakukan, pendampingan tetap diberikan selama 2 minggu.

\section{HASIL DAN PEMBAHASAN}

Kegiatan pengabdian ini dilakukan mulai dari tahap persiapan, tahap pelaksanan (seminar, pelatihan dan pendampingan), evaluasi.

Antusias berbagai komponen guru dan dosen bukan hanya yang ada di makassar, tetapi diikuti juga oleh dari komponen guru dan dosen dari daerah lain di seluruh Indonesisa. Mereka ikut berpartisipasi sebagai peserta Workshop LMS With "Edmodo.

Beberapa metode pembelajaran selama ini menggunakan metode sosial media saja, sehingga dengan adanya kegiatan pelatihan ini pembelajaran dapat dilakukan dengan menggunakan E-Learning Edmodo.

Hasil pelaksanaan kegiatan Pengabdian Pada Masyarakat secara keseluruhan dapat dilihat dari beberapa komponen berikut ini :

a) Ketercapaian Target Jumlah Peserta

Target peserta seminar dan berbagai bentuk pelatihan sangat baik, hal terlihat dari keterlibatan berbagai komponen pengajar dan mahasiswa. Pelatihan ini dihadiri 370 peserta. Pendampingan dilakukan melalui grup whatsapp dan aplikasi
Edmodo itu sendiri agar para peserta benar-benar medapatkan pengetahuan dan keterampilan tentang penggunaan Aplikasi E-Learning Edmodo.

b) Ketercapaian Tujuan

Ketercapaian tujuan dari kegiatan pengabdian pada masyarakat ini dapat dinilai baik. Dimana selama dalam proses kegiatan ini tingkat kesadaran pengajar pentingnya mengenal E-Learning "Edmodo" dan bagaimana menggunakan aplikasi Edmodo ini. Selama kegiatan ini peserta di bimbing langsung oleh pakar dari aplikasi ini

c) Ketercapaian Materi

Materi yang berikan narasumber dan simulasi langsung sudah dilaksanakan dengan baik dan sesuai dengan program kerja serta target yang telah ditetapkan. Pemilihan materi ditetapkan setelah melakukan tahapan persiapan dengan cara survey akan kebutuhan dari permasalahan proses belajar mengajar guru dan siswa

d) Kemampuan Peserta dalam Mengikuti Setiap Proses Kegiatan

Kemampuan peserta yang menjadi sasaran dalam kegiatan prngabdian pada masyrakat ini dinilai baik, dimana antusiasme mereka dalam mengikuti setiap kegiatan yang telah di rancang sangat responsive.

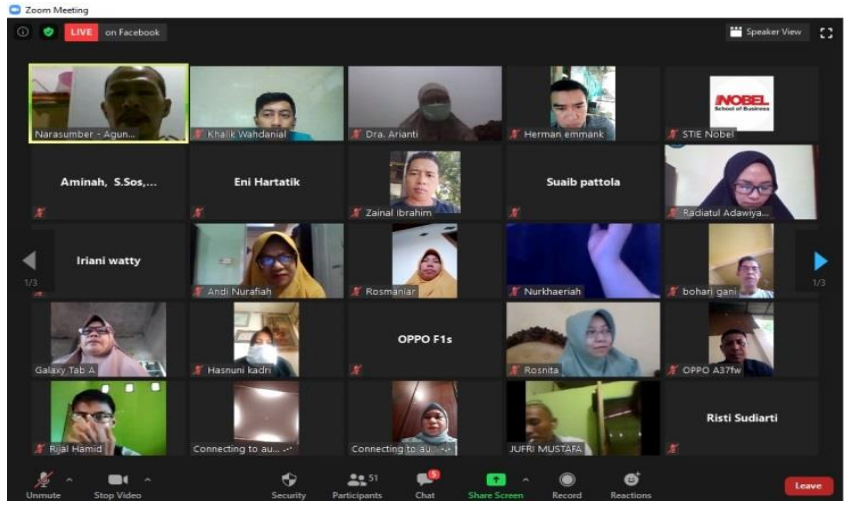

Gambar 1. Dokumentasi Kegiatan Workshop

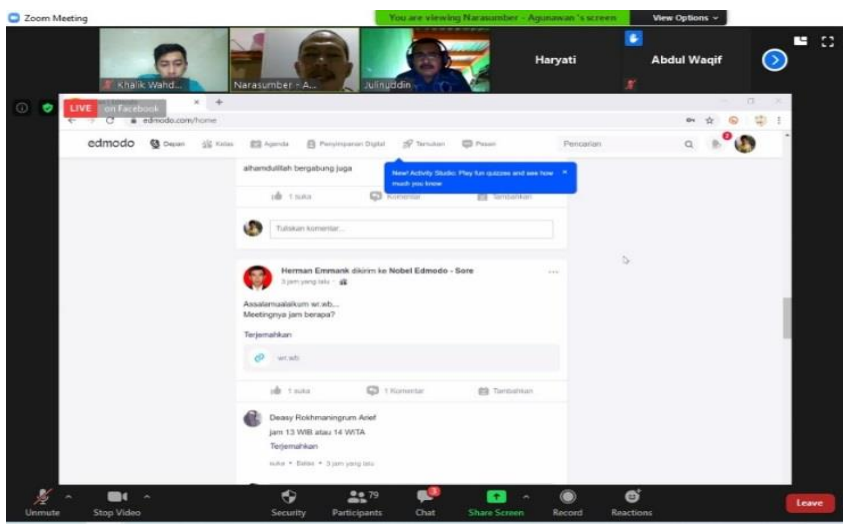

Gambar 2. Dokumentasi Kegiatan Pelatihan 


\section{KESIMPULAN}

Berdasarkan hasil kegiatan yang telah dilakukan terdapat poin-poin sebagai berikut :

1. Pengetahuan dan pemahaman pelaku usaha berkaitan dengan semangat kewirausahaan.

2. Pelatihan yang dilakukan dapat meningkatkan jiwa wirausaha dan semangat kerja pelaku usaha dalam menjalankan kegiatan usaha yang benar dan optimal.

3. Hasil kegiatan pelatihan pengabdian masyarakat menunjukkan pelatihan kewirausahaan ada pada setiap peserta dan membuat semangat bisnis mereka lebih baik.

\section{SARAN}

Guru dan dosen diharapkan lebih menguasai dan memahami yang namanya LMS (Learning Management System) agar proses belajar mengajar lebih efektif.

\section{DAFTAR PUSTAKA}

Agunawan. (2020). LMS - Edmodo Solusi Belajar Dari Rumah - Sebuah Pendekatan
Tanya Jawab

Asbara, N. W. (2020). Pemanfaatan Augmented Reality (AR) Sebagai Media Pembelajaran Interaktif Pengenalan Huruf Hijaiyyah Berbasis Android. Journal of Computer Science and Visual Communication Design, 5(1), 1-9.

Kristiani, D. (2016). E-learning dengan aplikasi edmodo di sekolah menengah kejuruan. Seminar Nasional Multi Disiplin Ilmu Unisbank 2016.

Latief, F., \& Nur, Y. (2019). Technology Acceptance Model (Tam) terhadap minat konsumen sistem pembayaran Gopay pada layanan Gojek. Bongaya Journal for Research in Management (BJRM), 2(2), 111.

Muhson, A. (2010). Pengembangan media pembelajaran berbasis teknologi informasi. Jurnal pendidikan akuntansi indonesia, 8(2).

Saifuddin, M. F. (2018). E-learning dalam persepsi mahasiswa. Jurnal Varidika, 29(2), 102-109. 